\title{
Molecular Adaptation of Modern Human Populations
}

\author{
Hong Shi and Bing Su \\ State Key Laboratory of Genetic Resources and Evolution, Kunming Institute of Zoology and Kunming Primate Research Centre, \\ Chinese Academy of Sciences, Kunming 650223, China
}

Correspondence should be addressed to Hong Shi, shihong@mail.kiz.ac.cn and Bing Su, sub@mail.kiz.ac.cn

Received 11 October 2010; Accepted 14 December 2010

Academic Editor: Darren Curnoe

Copyright $\odot 2011$ H. Shi and B. Su. This is an open access article distributed under the Creative Commons Attribution License, which permits unrestricted use, distribution, and reproduction in any medium, provided the original work is properly cited.

\begin{abstract}
Modern humans have gone through varied processes of genetic adaptations when their ancestors left Africa about 100,000 years ago. The environmental stresses and the social transitions (e.g., emergence of the Neolithic culture) have been acting as the major selective forces reshaping the genetic make-up of human populations. Genetic adaptations have occurred in many aspects of human life, including the adaptation to cold climate and high-altitude hypoxia, the improved ability of defending infectious diseases, and the polished strategy of utilizing new diet with the advent of agriculture. At the same time, the adaptations once developed during evolution may sometimes generate deleterious effects (e.g., susceptibility to diseases) when facing new environmental and social changes. The molecular (especially the genome-wide screening of genetic variations) studies in recent years have detected many genetic variants that show signals of Darwinian positive selection in modern human populations, which will not only provide a better understanding of human evolutionary history, but also help dissecting the genetic basis of human complex diseases.
\end{abstract}

\section{Origins of Modern Humans}

Two schools holding different opinions about where and when modern humans originated have been debating for more than two decades. The "Out-of-Africa" hypothesis of modern human origin was initially proposed in the mid1980s [1,2] by studying the genetic variations of mitochondrial DNA (mtDNA), and it was suggested that modern humans first originated in Africa about 200 kya (thousand years ago) then expanded to the other parts of the world and completely replaced the local archaic populations [3]. On the contrary, the alternative hypothesis of "Multiregional Origin", suggested that modern humans were evolved not only in Africa but also in other continents, for example, East Asia and Europe independently [4], which explains the abundant hominid fossils unearthed outside of Africa and the evolutionary continuity not only in morphological traits but also in the spatial and temporal distributions $[5,6]$.

The "Multiregional Origin" hypothesis has been supported mostly by archeological data, while the "Out-ofAfrica" hypothesis has been supported by both extensive genetic and archaeological evidence [1, 7-15]. By molecular dating, the most recent common ancestor of modern humans emerged only about 100-200 kya ago $[8,10,13,16-$ 19], which is consistent with the fossil and culture records of anatomical modern humans firstly appearing in Africa about 150-200 kya ago $[17,20]$.

The Old World (including Africa, Europe, and Asia) is the area where the multiregionalists claimed independent origins of modern humans [21]. However, besides the numerous genetic studies on current human populations worldwide, genetic data from human fossil samples also supports the "Out-of-Africa" hypothesis. The ancient DNA analysis implies that Neanderthals is not the ancestor of modern Europeans, and they have diverged from modern humans for at least $300 \mathrm{Kya}$ [22-24], although a recent study suggested potential (but rather limited) gene flow between Neanderthals and modern humans [25].

East Asia is one of the most important regions for studying evolution and genetic diversity of human populations [26]. A great deal of efforts has been put on the origin of East Asian using different genetic markers. The autosomal $[7,9,15,27]$, mtDNA (mitochondrial DNA) [13, 28-33] and $\mathrm{Y}$ chromosome $[11,34-38]$ lines of evidence all support 
an African ancestor of modern humans in East Asia. In addition, the genetic data also revealed the prehistoric migratory routes from Africa to East Asia. They first reached the southern part of East Asia (mainland Southeast Asia) [38, 39] then migrated northward to mainland China, Siberia, and eventually to America. There was also an early southward migration from mainland Southeast Asia to Australia and Papua New Guinea [37, 39, 40].

\section{Prehistoric Migrations of Modern Humans and Natural Selection}

According to the genetic data as well as the fossil records, the exodus of modern humans from Africa only started less than $100 \mathrm{Kya}$, initially along the costal line, and then gradually expanded northward to high-altitude areas in the northern hemisphere and southward to Australia, and relatively recently to South America, where they had been facing different environments from their homeland in Africa.

Although the origin and expansion of modern humans is relatively recent, there are extensive variations in modern human populations in view of phenotypic traits (e.g., skin color) as well as genetic make-up (e.g., the diverse Y chromosome haplotypes). At DNA sequence level, most of the variations are considered neutral, that is, doing neither good nor bad, but genetic studies in the past ten years have revealed many examples of molecular adaptations during the prehistoric migrations of modern human populations when they encountered new environments and developed adaptive genetic features through natural selection.

Modern humans have occupied almost all possible environments globally since exiting Africa about 100 Kya. Both behavioral and biological adaptations have contributed to their success in surviving the rigors of climatic extremes including cold, strong UV radiation, and high-altitude, and so forth. Throughout their evolutionary history, human populations have been exposed to myriad pressures from natural selection. The confronted stresses (selective pressures) are the important factors influencing the fate of the variations in the human genetic background. The genetic changes arising from variable metabolic efficiency, resistance to pathogens, and even the preferences of potential mates, and natural selection produce the adaptable phenotypic patterns [41].

The process of natural selection induces an increase or decrease of the frequency of mutations that have an effect on fitness, and the favored heritable traits become dominant in successive generations. The advantageous mutations can rapidly increase in frequency coupled with linked variants (the hitchhiking effect), due to Darwinian positive selection [42-45]. Given enough time, an advantageous mutation eventually would accumulate from a single event to fixation in human populations. When selection is still ongoing, the genetic locus under selection is usually polymorphic, that is, on the way to fixation. In contrast, the deleterious mutations generally keep low frequencies because of their adverse effect on fitness. At the same time, both natural selection and demographic history can cause the departures from a neutral equilibrium. A rapidly expanding population can result in frequency increase of rare polymorphisms, but a population bottleneck would cause the loss of rare variants. Hence, when detecting the molecular signatures of natural selection, we need to consider these confounding factors.

Additionally, analyses on the genetic variation among populations will not only help understand the molecular mechanism of adaptation, but will also aid in identifying the differential susceptibility to diseases, differential responses to pharmacological agents, human evolutionary history, and the complex interactions of genetic variations with environmental factors.

\section{Genetic Adaptations of Modern Humans}

During the expansion of modern humans from Africa to the other parts of the world, they should have confronted different environmental changes, and the external stresses triggered the selective events during the course of migrations. For example, the heat stress had led to the emergence of hairless skin and more efficient sweating of modern humans, which was suggested as an adaptive feature for efficient hunting during the early history of modern humans in Africa [46].

At the same time, the environmental UV and the low temperature (when modern humans migrated to highlatitude areas) would have imposed additional selection on the hairless skin [47]. One reported example is the latitudedependent distribution of a sequence polymorphism of the p53 gene. The p53 codon 72 has a common variant from proline to arginine (p53 Pro72Arg), and p53 Arg72 can partially escape the negative regulation by iASPP and lead to a prolonged half life of p53. Hence, p53 Arg72 has more activity than p53 Pro72 [48, 49]. When our ancestors left Africa and started to explore northward to high-latituderegions, the p53 Arg72 was selected by winter temperature and enriched in the populations living in the north. The more active p53 is more efficient in regulating processes such as metabolism (e.g., heat generating) and embryo implantation, which would result in higher fitness levels. Interestingly, this is only one side of the story. p53 has a major negative regulator, the MDM2 gene, counteracting with p53 in a "Yin and Yang" fashion. Mdm2 has a common polymorphism, MDM2 SNP309 (rs2279744), which is located in the MDM2 promoter sequence. A single-nucleotide change from $\mathrm{T}$ to $\mathrm{G}$ creates a binding site for the transcription factor SP1. As a result, the homozygotes for the $G$ allele express more Mdm2 mRNA and protein compared to the homozygotes for the T allele [50]. Population data in both Europe and East Asia showed that the MDM2 SNP309G/G is selected by low UV radiation exposure. Migration of modern humans northwards to lower UV regions requires less p53 in order to prevent any adverse effects of p53 hyperactivity such as embryonic death. The higher level of Mdm2 is selected to counteract the high p53 levels resulting from the positive selection of the p53Arg72 allele, thereby conferring a selective advantage. This would prevent an overactive p53 pathway, while still enabling p53 to function as a tumor suppressor. The selection ensures the low p53 levels when UV poses no risk to health and survival and also provides a selective advantage, adapting to new environments by keeping 
the balance between p53 and MDM2. The signature of positive selection indicates that selection on p53Arg72 and MDM2 SNP309G/G is strong, leading to the rapid formation of an allele frequency gradient across different latitudes. A well-regulated p53 pathway has been shown to be crucial in many organisms, not only for tumor suppression but also for proper embryonic development and inflammatory responses [47].

Besides the climatic factors modern humans had to cope with during their expansion, there are other factors, such as food, life style, and pathogens, which could also provoke selection. Recently, the genome-wide genetic analyses in East Asian populations have indicated that a considerable number of genes have changed significantly among clusters that are involved in cardiotoxicity, hepatotoxicity, and nephrotoxicity [51]. This suggests that there had been selective forces driving the genes to convey metabolic detoxication to fight with those toxic substances absorbed from new food.

Food and life styles have influenced our genetic makeup, especially during the transition from hunting-gathering to farming societies during Neolithic time (starting about $10 \mathrm{Kya})$. Several reported good examples include alcohol drinking, starch-food diet, and milk consumption. The studies on human ADH (alcohol dehydrogenase) gene have suggested Darwinian positive selection on the genetic variation of ADH1B His47 [52-54]. Alcohol consumption is a recent agriculture-related life style, and the adaptive selection has begun about 10 Kya [55]. One reported study showed the strikingly high frequency of ADH1Bhis47 in southeastern China where the earliest rice domestication originated. Rice has been used as the material to produce fermented food and beverages for a long time in southern China since early Neolithic time. The fermentation helps to preserve and enhance the nutritional value of foods and beverages. However, alcohol can lead to addiction and cause damages to human bodies, including nervous system dysfunction, tumor genesis, innate immune system modulation, and fetal alcohol syndrome. Therefore, genes involved in the ethanol metabolic pathway have become the target of selection when the ethanol-containing food and beverages had been routinely consumed by Neolithic populations in southern China. The systemic population analysis across China indicated that the ADH1B Arg47His sequence polymorphism is under the selection of alcohol consumption. The change of amino acid from Arg to His causes enzymatic activity alteration. The derived allele, $\mathrm{ADH} 1 \mathrm{~B}^{*} 47 \mathrm{His}$, changes the pKa of the enzyme from 8.5 to 10.0 which is associated with 40-to 100-fold increase in $\mathrm{Km}$ and Vmax of alcohol metabolism. The individuals carrying the $\mathrm{ADH} 1 \mathrm{~B} * 47 \mathrm{His}$ allele can rapidly metabolize the administered alcohol, therefore, resulting in quick eradication of ethanol, and therefore lower local exposure. On the other hand, the rapid eradication of alcohol also leads to the quick accumulation of aldehyde, the substance which causes flushing when people drink, preventing from overconsumption and possibly addiction. The ADH1B*47His is selected by the ethanol-containing food routinely consumed, and it provides a mechanism to utilize the benefit of fermented food and at the same time eliminating the adverse effects of alcohol [55].
The other two well-studied examples are the copy number variation of amylase gene for starchy food and the regulatory sequence variations of lactase for milk [5658]. Starch consumption is a characteristic of agricultural societies. This adaptation raises the possibility of selective pressures on amylase, which is responsible for starch hydrolysis. The higher copy number of the salivary amylase gene (AMY1) is identified with positive selection by high-starch diets [58]. Higher AMY1 copy numbers and protein levels would improve the digestion of starchy foods and may buffer against the fitness-reducing effects of intestinal disease.

Lactase persistence (LP) is the ability to digest milk and other dairy products at adulthood, which is the acquired genetic adaptation, independently emerged in northern Europe and Africa. LP is most common in the nomadic tribes that practice pastoralism and is rare in the agricultural populations [59]. The studies indicated that LP is strongly associated with the $\mathrm{T}$ allele at a $\mathrm{C} / \mathrm{T}$ SNP which is located at $13910 \mathrm{bp}$ upstream from the lactase gene (LCT) $[60,61]$. The T-13910 haplotype in the LCT promoter can enhance gene transcription $[56,57]$. The LCT gene showed the strongest signal of positive selection in northern Europeans [44, 62].

The SNP T-13910 (rs4988235) is only present in a few African populations [63-65], suggesting that the T-13910 allele may not contribute to the lactase persistence in most Africans. A study on a large African population identified three SNPs, which are located within 100 bp of the European LP-associated SNP T-13910. They are significantly associated with the LP trait in African populations [66]. SNP C-14010 is common in Tanzanian and Kenyan pastoralist populations, whereas the SNP G-13915 and SNP G-13907 are common in northern Sudanese and Kenyans. The SNP C-14010, SNP G13915, and SNP G-13907 in the LAC promoter can enhance gene transcription as the SNP T-13910 does in Europeans [66]. Genotyping across a 3-Mb region in these populations indicated that the African LP-associated variants are different from those in Europeans. This is an example of convergent and adaptive evolution due to the same selective pressure of the cattle domestication and adult milk consumption in Europeans and Africans.

\section{Adaptive Evolution and Pathogen Resistance in Modern Humans}

An important human adaptation is the ability to taste bitter compounds. The selective advantage of bitter taste can avoid ingesting toxic substances in plants. The systematic analysis of nucleotide and haplotype variations of bitter taste genes identified that these genes had been under natural selection [67]. For example, genetic analyses have detected signatures of balancing selection at the TAS2R38 locus in continental populations [68]. It is hypothesized that individuals with a low sensitivity to the bitter taste of cyanogenic compounds may have a survival advantage against malarial infection through a higher intake of these bitter compounds $[69,70]$, and the cyanide can inhibit the normal development of the $P$. falciparum parasite in vitro [71].

In addition, host genetic variation plays a key role in infectious disease susceptibility of humans. Through 
recurrent exposure to pathogens, the genetic adaptations evolve to provide resistance on infection, and the immune systems could be subject to different pressures from bacteria, virus, and other pathogens.

Malaria is a major killer worldwide and its infection is the strongest selective force in recent human evolution. Most genetic adaptation to resistant malarial infection has impact on red blood cells or on immune response. The adaptations include the hemoglobinopathies gene: $\alpha$-globin $\left(\mathrm{alpha}^{+}\right.$thalassemia), $\beta$-globin variants ( $\mathrm{HbC}$ and $\mathrm{HbS}$ ), a number of HLA alleles, and the glucose 6-phosphate dehydrogenase (G6PD) A allele [72-77]. Common hemoglobinopathies, sickle cell trait and $\alpha^{+}$thalassemia, confer partial resistance to the fatal forms of malaria, which presents particularly high frequencies in the populations of the malaria areas in Africa. The disorders of hemoglobin structure, $\alpha^{+}$thalassemia, can protect against malaria infection from the transmission intensity and suggest the selection of the $\alpha^{+}$allele by malaria [73]. The $\beta$-globin variants, hemoglobin $\mathrm{C}$ ( $\mathrm{HbC}$; beta6Glu>Lys) or hemoglobin S (HbS; beta6Glu>Val), can stimulate a higher immune response against the malaria antigens, suggesting that both $\mathrm{HbC}$ and $\mathrm{HbS}$ affect the early development of naturally acquired immunity against malaria [76].

The human leukocyte antigen (HLA) system is highly polymorphic among human populations, and the different components of the disease drive the evolutionary selection on HLA antigens. The selections on a few HLA alleles associated with resistance to malaria infection have been found in different populations, which have the unique HLA antigens prevalent in different malaria endemic areas. The HLA allele B*53 and DRB1*1302 are resistant to malaria in Gambia, Africa [78]. The resistant alleles are prevalent in multiple geographic areas, including the alleles of $\mathrm{B}^{*} 53$, and $A^{*} 2$ in Maharashtra, DQB1, 0203, B*35, and B*27 in Mumbai, and $A^{*} 0211$ in New Delhi, India [79-81]. Additionally, the alleles B*56, DRB1*1001 and DPB1*0501 have been found in Thailand, HLA-DQ1*0502 in Vietnam and $\mathrm{B}^{*} 1513$ in Malaysia [82-85].

The common polymorphism of G6PD A allele causes G6PD deficiency, which confers resistance to malaria [8690]. G6PD A allele is associated with about 50\% reduced risk of severe malaria in female heterozygotes and in male hemizygotes [91]. The geographical distribution of G6PD deficiency is consistent with evolutionary selection by malaria [87], and analysis of haplotypic structure at the G6PD locus supports the recent positive selection of the A allele $[89,90]$.

Another well-known example is the recent enrichment (less than 500 years) of mutations in several HIV-infection related genes. For example, the $\Delta 32$ mutation at the chemokine receptor 5 (CCR5) gene can defend against HIV virus infection [92].

\section{Adaptive Evolution and Human Complex Diseases}

Metabolic syndrome (including obesity, Type 2 diabetes, and hypertension) is one of the major human complex diseases, and current prevalence of metabolic syndrome attributes to the evolutionary history of modern humans. The most well-known theory explaining the prevalence of metabolic syndrome in modern societies is the "thrift gene" hypothesis [93]. Before agriculture emerged about 10,000 years ago, modern humans had lived in a life style of hunting and gathering, which would easily lead to frequent cycles of feast and famine. Consequently, the genetic variants had been selected to promote the efficient absorption, storage, and utilization of nutrients in this environment, that are now maladaptive in modern civilization, increasing risk for metabolic diseases [94, 95]. For example, obesity is such a serious disease in modern society, in which agriculture provide exceedingly enough food to people. The adaptation of the efficient absorption, storage and utilization of nutrients would now produce side effect, and it becomes a severe problem to current human populations.

Salt retention is an adaptive character to ancient humans living in hot, humid areas, who consumed low levels of dietary salt [96]. The genetic polymorphisms that promote salt retention were selected in hot and humid environments, but now became a risk factor for hypertension. Genetic adaptations to a low-salt environment in the ancestral populations have turned into a risk for hypertension in current populations living in a high-salt environment [96].

\section{Adaptive Evolutions under Extreme Environments}

In the recent 100,000 years, modern humans have occupied almost all possible environments, and the adaptations have contributed to their success in surviving the environmental rigors. Among these environmental stresses, high-altitude hypoxia is the only condition in which traditional technology is incapable of mediating its effects. The high-altitude natives including Tibetans and Andeans have developed routes to high-altitude adaptation [97]. Tibetans are likely the most adaptive population for high-altitude hypoxia, which is reflected by the elevated resting ventilation and low hemoglobin concentration compared to acclimatized lowlanders. In contrast, Andeans have developed a different strategy by increasing their hemoglobin concentrations and oxygen saturation [97]. The molecular mechanisms of these two high-altitude adaptation routes seem to be different [97].

Recent genome-wide genetic studies suggested that the genes involved in response for hypoxia are under strong natural selection. EPAS1 and EGLN1, the two hypoxiarelated genes, were shown under strong natural selection in Tibetans, and there are several candidate sequence variations showing significant association with hemoglobin levels [98100]. The genetic data suggested that during the long-term occupation of high-altitude areas, the functional sequence variations for acquiring biological adaptation to highaltitude hypoxia have been enriched in Tibetan populations though the detailed molecular mechanism is yet to be revealed. 


\section{Perspectives}

Modern human populations have experienced varied environmental and social transitions since they left Africa about 100 Kya. Current proceedings in genetic studies have revealed that the observed molecular adaptations of modern human are usually regional events, reflecting the history of encountering different environments during the prehistoric migrations outside of Africa. At the same time, the genetic adaptations once developed during evolution may become deleterious at a later stage with the change of environments and life styles. With the rapid progress of genome-sequencing technology, there will be a large quantity of genome-wide variation data across the populations worldwide. More genetic loci will be identified contributing to varied adaptive features of modern human populations, which will not only provide a better understanding of human evolutionary history, but will also aid in dissecting the genetic basis of human complex diseases.

\section{References}

[1] C. B. Stringer and P. Andrews, "Genetic and fossil evidence for the origin of modern humans," Science, vol. 239, no. 4846, pp. 1263-1268, 1988.

[2] G. Brauer, The Origins of Modern Humans: A World Survey of the Fossil Evidence, John Wiley \& Sons, New York, NY, USA, 1984.

[3] A. C. Wilson and R. L. Cann, "The recent African genesis of humans," Scientific American, vol. 266, no. 4, pp. 68-73, 1992.

[4] A. G. Thorne and M. H. Wolpoff, "The multiregional evolution of humans," Scientific American, vol. 266, no. 4, pp. 76-82, 1992.

[5] D. A. Etler, "The fossil evidence for human evolution in Asia," Annual Review of Anthropology, vol. 25, no. 1, pp. 275-301, 1996.

[6] H. C. Wu, F. E. Poirier, and X. Z. Wu, Human Evolution in China: A Metric Description of the Fossils and a Review of the Sites, Oxford University Press, Oxford, UK, 1995.

[7] A. M. Bowcock, A. Rulz-Linares, J. Tomfohrde, E. Minch, J. R. Kidd, and L. L. Cavalli-Sforza, "High resolution of human evolutionary trees with polymorphic microsatellites," Nature, vol. 368, no. 6470, pp. 455-457, 1994.

[8] R. L. Cann, M. Stoneking, and A. C. Wilson, "Mitochondrial DNA and human evolution," Nature, vol. 325, no. 6099, pp. 31-36, 1987.

[9] J. Y. Chu, W. Huang, S. Q. Kuang et al., "Genetic relationship of populations in China," Proceedings of the National Academy of Sciences of the United States of America, vol. 95, no. 20, pp. 11763-11768, 1998.

[10] M. F. Hammer, "A recent common ancestry for human Y chromosomes," Nature, vol. 378, no. 6555, pp. 376-378, 1995.

[11] Y. Ke, B. Su, X. Song et al., "African origin of modern humans in East Asia: a tale of 12,000 Y chromosomes," Science, vol. 292, no. 5519, pp. 1151-1153, 2001.

[12] L. Quintana-Murci, O. Semino, H. J. Bandelt, G. Passarino, K. McElreavey, and A. S. Santachiara-Benerecetti, "Genetic evidence of an early exit of Homo sapiens sapiens from Africa through eastern Africa," Nature Genetics, vol. 23, no. 4, pp. 437-441, 1999.
[13] L. Vigilant, M. Stoneking, H. Harpending, K. Hawkes, and A. C. Wilson, "African populations and the evolution of human mitochondrial DNA," Science, vol. 253, no. 5027, pp. 15031507, 1991.

[14] R. C. Walter, R. T. Buffler, J. H. Bruggemann et al., "Early human occupation of the Red Sea coast of Eritrea during the last interglacial," Nature, vol. 405, no. 6782, pp. 65-69, 2000.

[15] S. A. Tishkoff, E. Dietzsch, W. Speed et al., "Global patterns of linkage disequilibrium at the CD4 locus and modern human origins," Science, vol. 271, no. 5254, pp. 1380-1387, 1996.

[16] J. D. Clark, Y. Beyene, G. WoldeGabriel et al., "Stratigraphic, chronological and behavioural contexts of Pleistocene Homo sapiens from Middle Awash, Ethiopia," Nature, vol. 423, no. 6941, pp. 747-752, 2003.

[17] T. D. White, B. Asfaw, D. DeGusta et al., "Pleistocene Homo sapiens from Middle Awash, Ethiopia," Nature, vol. 423, no. 6941, pp. 742-747, 2003.

[18] P. A. Underhill, G. Passarino, A. A. Lin et al., "The phylogeography of Y chromosome binary haplotypes and the origins of modern human populations," Annals of Human Genetics, vol. 65, no. 1, pp. 43-62, 2001.

[19] P. A. Underhill, P. Shen, A. A. Lin et al., "Y chromosome sequence variation and the history of human populations," Nature Genetics, vol. 26, no. 3, pp. 358-361, 2000.

[20] I. McDougall, F. H. Brown, and J. G. Fleagle, "Stratigraphic placement and age of modern humans from Kibish, Ethiopia," Nature, vol. 433, no. 7027, pp. 733-736, 2005.

[21] M. H. Wolpoff, J. Hawks, and R. Caspari, "Multiregional, not multiple origins," American Journal of Physical Anthropology, vol. 112, no. 1, pp. 129-136, 2000.

[22] M. Krings, C. Capelli, F. Tschentscher et al., "A view of Neandertal genetic diversity," Nature Genetics, vol. 26, no. 2, pp. 144-146, 2000.

[23] M. Krings, A. Stone, R. W. Schmitz, H. Krainitzki, M. Stoneking, and S. Paabo, "Neandertal DNA sequences and the origin of modern humans," Cell, vol. 90, no. 1, pp. 1930, 1997.

[24] I. V. Ovchinnikov, A. Götherström, G. P. Romanova, V. M. Kharitonov, K. Lidén, and W. Goodwin, "Molecular analysis of Neanderthal DNA from the northern Caucasus," Nature, vol. 404, no. 6777, pp. 490-493, 2000.

[25] R. E. Green, J. Krause, S. E. Ptak et al., "Analysis of one million base pairs of Neanderthal DNA," Nature, vol. 444, no. 7117, pp. 330-336, 2006.

[26] L. L. Cavalli-Sforza, "The Chinese human genome diversity project," Proceedings of the National Academy of Sciences of the United States of America, vol. 95, no. 20, pp. 11501-11503, 1998.

[27] L. Jin, P. A. Underhill, V. Doctor et al., "Distribution of haplotypes from a chromosome 21 region distinguishes multiple prehistoric human migrations," Proceedings of the National Academy of Sciences of the United States of America, vol. 96, no. 7, pp. 3796-3800, 1999.

[28] S. W. Ballinger, T. G. Schurr, A. Torroni et al., "Southeast Asian mitochondrial DNA analysis reveals genetic continuity of ancient mongoloid migrations," Genetics, vol. 130, no. 1, pp. 139-152, 1992.

[29] S. Harihara, N. Saitou, M. Hirai et al., "Mitochondrial DNA polymorphism among five Asian populations," American Journal of Human Genetics, vol. 43, no. 2, pp. 134-143, 1988.

[30] B. Wen, H. Li, S. Gao et al., "Genetic structure of HmongMien speaking populations in East Asia as revealed by 
mtDNA lineages," Molecular Biology and Evolution, vol. 22, no. 3, pp. 725-734, 2005.

[31] B. Wen, X. Xie, S. Gao et al., "Analyses of genetic structure of Tibeto-Burman populations reveals sex-biased admixture in southern Tibeto-Burmans," American Journal of Human Genetics, vol. 74, no. 5, pp. 856-865, 2004.

[32] Y. G. Yao, Q. P. Kong, H. J. Bandelt, T. Kivisild, and YA. P. Zhang, "Phylogeographic differentiation of mitochondrial DNA in Han Chinese," American Journal of Human Genetics, vol. 70, no. 3, pp. 635-651, 2002.

[33] Y. G. Yao, W. S. Watkins, and Y. P. Zhang, "Evolutionary history of the mtDNA 9-bp deletion in Chinese populations and its relevance to the peopling of east and southeast Asia," Human Genetics, vol. 107, no. 5, pp. 504-512, 2000.

[34] L. Jin and B. Su, "Natives or immigrants: modern human origin in East Asia," Nature Reviews Genetics, vol. 1, no. 2, pp. 126-133, 2000.

[35] H. Shi, Y. L. Dong, B. Wen et al., "Y-chromosome evidence of southern origin of the East Asian-specific haplogroup O3M122," American Journal of Human Genetics, vol. 77, no. 3, pp. 408-419, 2005.

[36] H. Shi, H. Zhong, Y. Peng et al., "Y chromosome evidence of earliest modern human settlement in East Asia and multiple origins of Tibetan and Japanese populations," BMC Biology, vol. 6, no. 10, article 45, 2008.

[37] B. Su, L. Jin, P. Underbill et al., "Polynesian origins: insights from the Y chromosome," Proceedings of the National Academy of Sciences of the United States of America, vol. 97, no. 15, pp. 8225-8228, 2000.

[38] B. Su, J. Xiao, P. Underhill et al., "Y-chromosome evidence for a northward migration of modern humans into eastern Asia during the last Ice Age," American Journal of Human Genetics, vol. 65, no. 6, pp. 1718-1724, 1999.

[39] A. Thorne, R. Grün, G. Mortimer et al., "Australia’s oldest human remains: age of the Lake Mungo 3 skeleton," Journal of Human Evolution, vol. 36, no. 6, pp. 591-612, 1999.

[40] J. M. Bowler, H. Johnston, J. M. Olley et al., "New ages for human occupation and climatic change at Lake Mungo, Australia," Nature, vol. 421, no. 6925, pp. 837-840, 2003.

[41] M. Bamshad and S. P. Wooding, "Signatures of natural selection in the human genome," Nature Reviews Genetics, vol. 4, no. 2, pp. 99-111, 2003.

[42] E. E. Harris and D. Meyer, "The molecular signature of selection underlying human adaptations," American Journal of Physical Anthropology, vol. 131, supplement 43, pp. 89130, 2006.

[43] R. Nielsen, I. Hellmann, M. Hubisz, C. Bustamante, and A. G. Clark, "Recent and ongoing selection in the human genome," Nature Reviews Genetics, vol. 8, no. 11, pp. 857-868, 2007.

[44] P. C. Sabeti, P. Varilly, B. Fry et al., "Genome-wide detection and characterization of positive selection in human populations," Nature, vol. 449, no. 7164, pp. 913-918, 2007.

[45] S. A. Tishkoff and B. C. Verrelli, "Patterns of human genetic diversity: implications for human evolutionary history and disease," Annual Review of Genomics and Human Genetics, vol. 4, pp. 293-340, 2003.

[46] R. Boyd and J. Silk, How Humans Evolved, Norton, New York, NY, USA, 3rd edition, 2003.

[47] H. Shi, S. J. Tan, H. Zhong et al., "Winter temperature and UV are tightly linked to genetic changes in the p53 tumor suppressor pathway in Eastern Asia," American Journal of Human Genetics, vol. 84, no. 4, pp. 534-541, 2009.
[48] D. Bergamaschi, Y. Samuels, A. Sullivan et al., "iASPP preferentially binds $\mathrm{p} 53$ proline-rich region and modulates apoptotic function of codon 72-polymorphic p53," Nature Genetics, vol. 38, no. 10, pp. 1133-1141, 2006.

[49] M. E. Murphy, "Polymorphic variants in the p53 pathway," Cell Death and Differentiation, vol. 13, no. 6, pp. 916-920, 2006.

[50] G. L. Bond, W. Hu, E. E. Bond et al., "A single nucleotide polymorphism in the MDM2 promoter attenuates the p53 tumor suppressor pathway and accelerates tumor formation in humans," Cell, vol. 119, no. 5, pp. 591-602, 2004.

[51] S. Xu, X. Yin, S. Li et al., "Genomic dissection of population substructure of Han Chinese and its implication in association studies," American Journal of Human Genetics, vol. 85, no. 6, pp. 762-774, 2009.

[52] Y. Han, S. Gu, H. Oota et al., "Evidence of positive selection on a class I ADH locus," American Journal of Human Genetics, vol. 80, no. 3, pp. 441-456, 2007.

[53] H. Li, S. Gu, X. Cai et al., "Ethnic related selection for an ADH class I variant within East Asia," PLoS One, vol. 3, no. 4, Article ID e1881, 2008.

[54] H. Li, N. Mukherjee, U. Soundararajan et al., "Geographically separate increases in the frequency of the derived ADH1B*47His allele in eastern and western Asia," American Journal of Human Genetics, vol. 81, no. 4, pp. 842-846, 2007.

[55] Y. Peng, H. Shi, X. B. Qi et al., "The ADH1B Arg47His polymorphism in East Asian populations and expansion of rice domestication in history," BMC Evolutionary Biology, vol. 10, no. 1, article 15, 2010.

[56] R. H. Lewinsky, T. G. K. Jensen, J. Møller, A. Stensballe, J. Olsen, and J. T. Troelsen, "T DNA variant associated with lactase persistence interacts with Oct-1 and stimulates lactase promoter activity in vitro," Human Molecular Genetics, vol. 14, no. 24, pp. 3945-3953, 2005.

[57] L. C. Olds and E. Sibley, "Lactase persistence DNA variant enhances lactase promoter activity in vitro: functional role as a cis regulatory element," Human Molecular Genetics, vol. 12, no. 18, pp. 2333-2340, 2003.

[58] G. H. Perry, N. J. Dominy, K. G. Claw et al., "Diet and the evolution of human amylase gene copy number variation," Nature Genetics, vol. 39, no. 10, pp. 1256-1260, 2007.

[59] E. J. Hollox, M. Poulter, M. Zvarik et al., "Lactase haplotype diversity in the old world," American Journal of Human Genetics, vol. 68, no. 1, pp. 160-172, 2001.

[60] N. S. Enattah, T. Sahi, E. Savilahti, J. D. Terwilliger, L. Peltonen, and I. Jarvela, "Identification of a variant associated with adult-type hypolactasia," Nature Genetics, vol. 30, no. 2, pp. 233-237, 2002.

[61] M. Poulter, E. Hollox, C. B. Harvey et al., “The causal element for the lactase persistence/non-persistence polymorphism is located in a $1 \mathrm{Mb}$ region of linkage disequilibrium in Europeans," Annals of Human Genetics, vol. 67, no. 4, pp. 298-311, 2003.

[62] B. F. Voight, S. Kudaravalli, X. Wen, and J. K. Pritchard, "A map of recent positive selection in the human genome," PLoS Biology, vol. 4, no. 3, Article ID e72, 2006.

[63] M. Coelho, D. Luiselli, G. Bertorelle et al., "Microsatellite variation and evolution of human lactase persistence," Human Genetics, vol. 117, no. 4, pp. 329-339, 2005.

[64] C. A. Mulcare, M. E. Weale, A. L. Jones et al., "The T allele of a single-nucleotide polymorphism $13.9 \mathrm{~kb}$ upstream of the lactase gene (LCT) (C-13.9kbT) does not predict or cause the 
lactase-persistence phenotype in africans," American Journal of Human Genetics, vol. 74, no. 6, pp. 1102-1110, 2004.

[65] S. Myles, N. Bouzekri, E. Haverfield, M. Cherkaoui, J. M. Dugoujon, and R. Ward, "Genetic evidence in support of a shared Eurasian-North African dairying origin," Human Genetics, vol. 117, no. 1, pp. 34-42, 2005.

[66] S. A. Tishkoff, F. A. Reed, A. Ranciaro et al., "Convergent adaptation of human lactase persistence in Africa and Europe," Nature Genetics, vol. 39, no. 1, pp. 31-40, 2007.

[67] U. Kim, S. Wooding, D. Ricci, L. B. Jorde, and D. Drayna, "Worldwide haplotype diversity and coding sequence variation at human bitter taste receptor loci," Human Mutation, vol. 26, no. 3, pp. 199-204, 2005.

[68] S. Wooding, U. K. Kim, M. J. Bamshad, J. Larsen, L. B. Jorde, and D. Drayna, "Natural selection and molecular evolution in PTC, a bitter-taste receptor gene," American Journal of Human Genetics, vol. 74, no. 4, pp. 637-646, 2004.

[69] N. Soranzo, B. Bufe, P. C. Sabeti et al., "Positive selection on a high-sensitivity allele of the human bitter-taste receptor TAS2R16," Current Biology, vol. 15, no. 14, pp. 1257-1265, 2005.

[70] F. Jackson, "Two evolutionary models for the interactions of dietary organic cyanogens, hemoglobins, and falciparum malaria," American Journal of Human Biology, vol. 2, pp. 521532, 1990.

[71] R. L. Nagel, C. Raventos, H. B. Tanowitz, and M. Wittner, "Effect of sodium cynanate on Plasmodium falciparum in vitro," Journal of Parasitology, vol. 66, no. 3, pp. 483-487, 1980.

[72] G. Ayodo, A. L. Price, A. Keinan et al., "Combining evidence of natural selection with association analysis increases power to detect malaria-resistance variants," American Journal of Human Genetics, vol. 81, no. 2, pp. 234-242, 2007.

[73] A. Enevold, M. Alifrangis, J. J. Sanchez et al., "Associations between $\alpha+$-thalassemia and Plasmodium falciparum malarial infection in Northeastern Tanzania," Journal of Infectious Diseases, vol. 196, no. 3, pp. 451-459, 2007.

[74] A. J. Frodsham and A. V. S. Hill, "Genetics of infectious diseases," Human Molecular Genetics, vol. 13, no. 2, pp. R187R194, 2004.

[75] A. V. S. Hill, "Aspects of genetic susceptibility to human infectious diseases," Annual Review of Genetics, vol. 40, pp. 469-486, 2006.

[76] F. Verra, J. Simpore, G. M. Warimwe et al., "Haemoglobin $\mathrm{C}$ and $\mathrm{S}$ role in acquired immunity against Plasmodium falciparum malaria," PLoS One, vol. 2, no. 10, article e978, 2007.

[77] T. N. Williams, T. W. Mwangi, S. Wambua et al., "Negative epistasis between the malaria-protective effects of $\alpha+-$ thalassemia and the sickle cell trait," Nature Genetics, vol. 37, no. 11, pp. 1253-1257, 2005.

[78] A. V. S. Hill, J. Elvin, A. C. Willis et al., "Molecular analysis of the association of HLA-B53 and resistance to severe malaria," Nature, vol. 360, no. 6403, pp. 434-439, 1992.

[79] U. Shankarkumar, K. Ghosh, S. Gupte, M. B. Mukherjee, and D. Mohanty, "Distribution of HLA antigens in Bhils and Pawras of Dhadgaon, Maharashtra. Indian 1999;10:173-8," Journal of Human Ecology, vol. 10, pp. 173-178, 1999.

[80] U. Shankarkumar, J. P. Devaraj, K. Ghosh, D. Karnad, K. Anand, and D. Mohanty, "HLA association in P. falciparum malaria patients from Mumbai, Western India," Indian Journal of Malariology, vol. 39, no. 3-4, pp. 76-82, 2002.
[81] N. K. Mehra, R. Jaini, R. Rajalingam, A. Balamurugan, and G. Kaur, "Molecular diversity of HLA-A*02 in Asian Indians: predominance of $A^{*} 0211$," Tissue Antigens, vol. 57, no. 6, pp. 502-507, 2001.

[82] H. Hananantachai, J. Patarapotikul, J. Ohashi, I. Naka, S. Looareesuwan, and K. Tokunaga, "Polymorphisms of the HLA-B and HLA-DRB1 genes in Thai malaria patients," Japanese Journal of Infectious Diseases, vol. 58, no. 1, pp. 2528, 2005.

[83] M. Busson, A. Vu Trieu, P. Labelle et al., "HLA-DRB1 and DQB1 allele distribution in the Muong population exposed to malaria in Vietnam," Tissue Antigens, vol. 59, no. 6, pp. 470-474, 2002.

[84] K. Hirayama, A. S. M. Zaidi, S. Lokman Hakim et al., "Molecular analysis of HLA-B in the Malaysian aborigines," Tissue Antigens, vol. 48, no. 6, pp. 692-697, 1996.

[85] H. A. F. Stephens, A. E. Brown, D. Chandanayingyong et al., "The presence of the HLA class II allele DPB $1 * 0501$ in ethnic Thais correlates with an enhanced vaccine-induced antibody response to a malaria sporozoite antigen," European Journal of Immunology, vol. 25, no. 11, pp. 3142-3147, 1995.

[86] U. Bienzle, O. Ayeni, A. O. Lucas, and L. Luzzatto, "Glucose6-phosphate dehydrogenase and malaria. Greater resistance of females heterozygous for enzyme deficiency and of males with non-deficient variant," Lancet, vol. 1, no. 7742, pp. 107110, 1972.

[87] M. Ganczakowski, M. Town, D. K. Bowden et al., "Multiple glucose 6-phosphate dehydrogenase-deficient variants correlate with malaria endemicity in the Vanuatu archipelago (southwestern Pacific)," American Journal of Human Genetics, vol. 56, no. 1, pp. 294-301, 1995.

[88] C. Ruwende and A. Hill, "Glucose-6-phosphate dehydrogenase deficiency and malaria," Journal of Molecular Medicine, vol. 76, no. 8, pp. 581-588, 1998.

[89] P. C. Sabeti, D. E. Reich, J. M. Higgins et al., "Detecting recent positive selection in the human genome from haplotype structure," Nature, vol. 419, no. 6909, pp. 832-837, 2002.

[90] S. A. Tishkoff, R. Varkonyi, N. Cahinhinan et al., "Haplotype diversity and linkage disequilibrium at human G6PD: recent origin of alleles that confer malarial resistance," Science, vol. 293, no. 5529, pp. 455-462, 2001.

[91] C. Ruwende, S. C. Khoo, R. W. Snow et al., "Natural selection of hemi- and heterozygotes for G6PD deficiency in Africa by resistance to severe malaria," Nature, vol. 376, no. 6537, pp. 246-249, 1995.

[92] J. Lama and V. Planelles, "Host factors influencing susceptibility to HIV infection and AIDS progression," Retrovirology, vol. 4, article 52, 2007.

[93] J. V. Neel, "Diabetes mellitus: a "thrifty" genotype rendered detrimental by "progress"?" American Journal of Human Genetics, vol. 14, pp. 353-362, 1962.

[94] A. Di Rienzo and R. R. Hudson, "An evolutionary framework for common diseases: the ancestral-susceptibility model," Trends in Genetics, vol. 21, no. 11, pp. 596-601, 2005.

[95] Y. C. Paradies, M. J. Montoya, and S. M. Fullerton, "Racialized genetics and the study of complex diseases: the thrifty genotype revisited," Perspectives in Biology and Medicine, vol. 50, no. 2, pp. 203-227, 2007.

[96] P. L. Balaresque, S. J. Ballereau, and M. A. Jobling, "Challenges in human genetic diversity: demographic history and adaptation," Human Molecular Genetics, vol. 16, no. 2, pp. R134-R139, 2007. 
[97] C. M. Beall, "Two routes to functional adaptation: Tibetan and Andean high-altitude natives," Proceedings of the National Academy of Sciences of the United States of America, vol. 104, no. 1, pp. 8655-8660, 2007.

[98] X. Yi, Y. Liang, E. Huerta-Sanchez et al., "Sequencing of 50 human exomes reveals adaptation to high altitude," Science, vol. 329, no. 5987, pp. 75-78, 2010.

[99] T. S. Simonson, Y. Yang, C. D. Huff et al., "Genetic evidence for high-altitude adaptation in Tibet," Science, vol. 329, no. 5987, pp. 72-75, 2010.

[100] C. M. Beall, G. L. Cavalleri, L. Deng et al., "Natural selection on EPAS1 (HIF2 $\alpha$ ) associated with low hemoglobin concentration in Tibetan highlanders," Proceedings of the National Academy of Sciences of the United States of America, vol. 107, no. 25, pp. 11459-11464, 2010. 

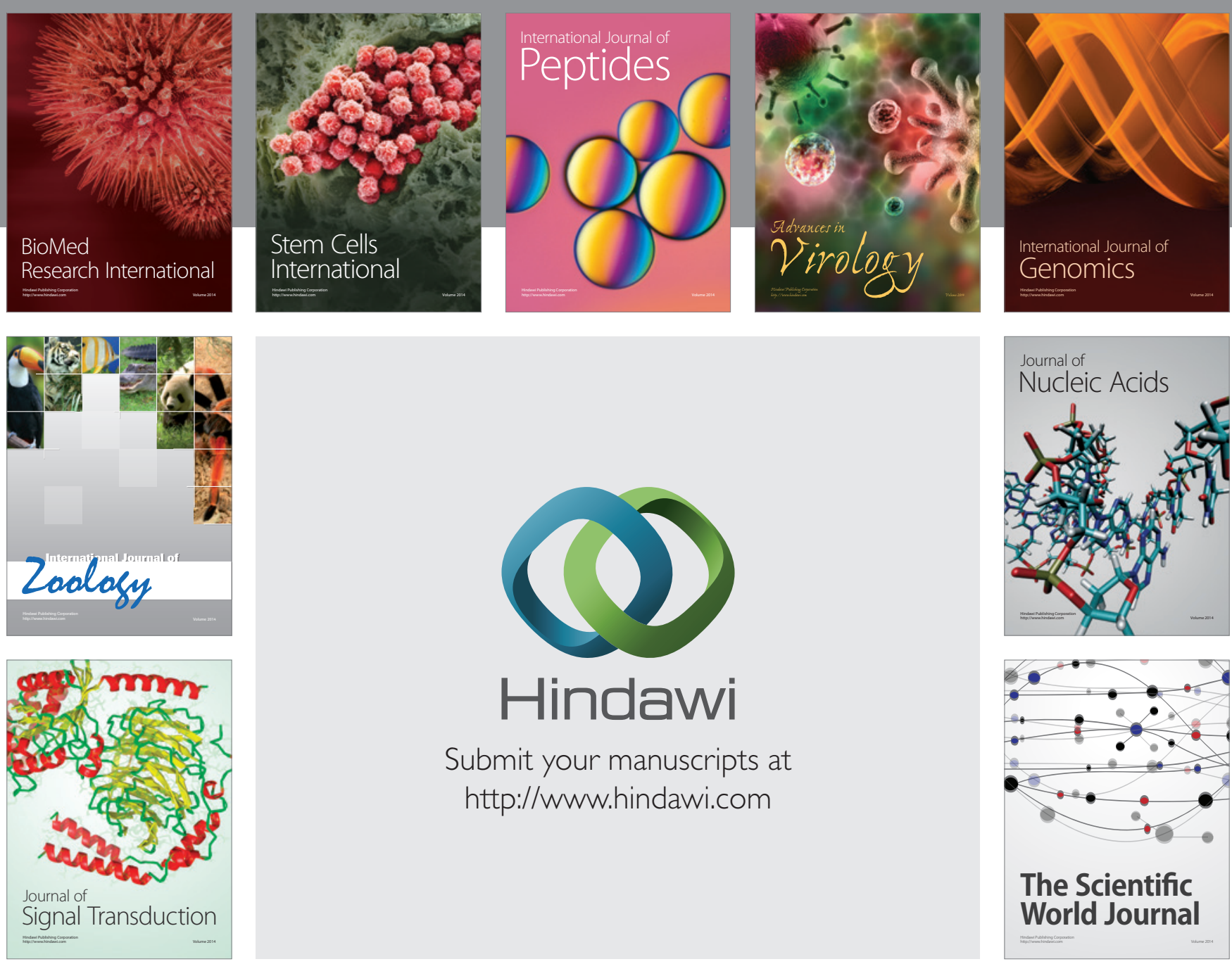

Submit your manuscripts at

http://www.hindawi.com
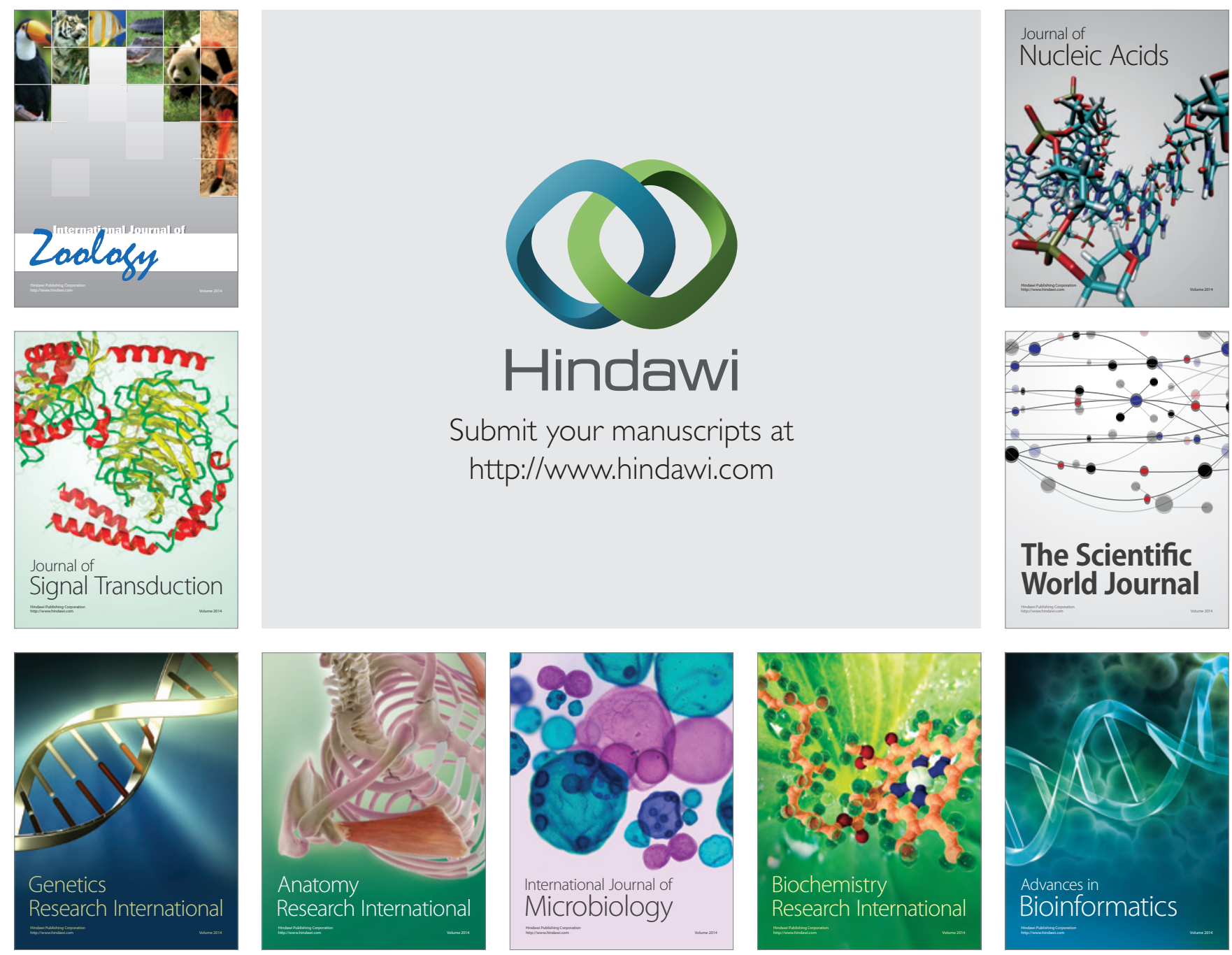

The Scientific World Journal
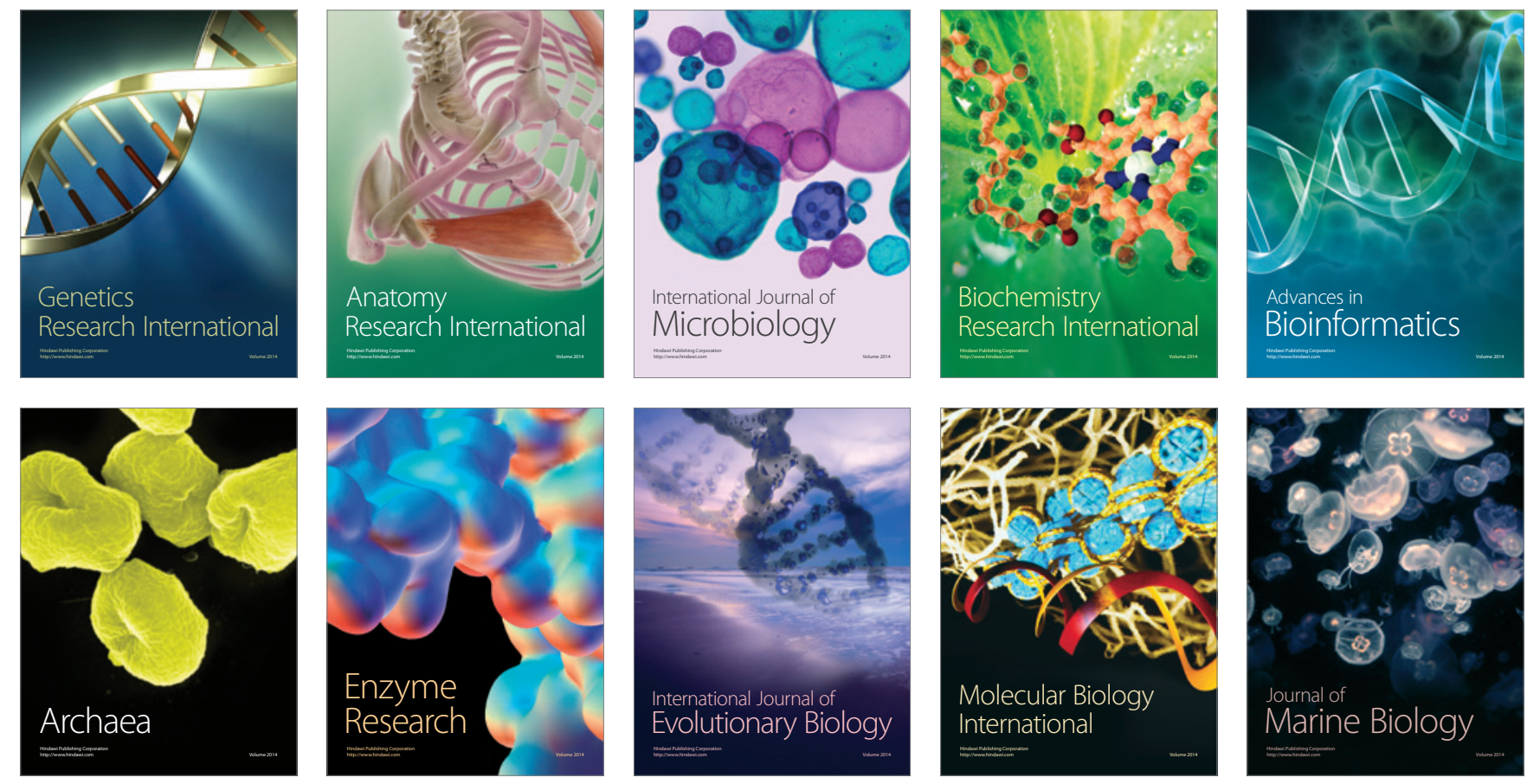